\title{
The use of sterilised polyester mosquito net mesh for inguinal hernia repair in Ghana
}

\author{
M. G. Clarke $\cdot$ C. Oppong $\cdot$ R. Simmermacher $\cdot$ \\ K. Park $\cdot$ M. Kurzer $\cdot$ L. Vanotoo $\cdot$ A. N. Kingsnorth
}

Published online: 19 March 2009

(C) Springer-Verlag 2009

\section{Erratum to: Hernia}

\section{DOI 10.1007/s10029-008-0460-3}

The fifth paragraph of the discussion should have read:

"DALYs were calculated in the reference case, with an average of 9.3 DALYs averted per person and a total of 1,053 DALYs averted in the study. 39\% were attributable to YLDs and $61 \%$ to YLLs. Cost effectiveness analyses identified an average cost of US $\$ 636.65$ from a provider perspective, and $\$ 609.90$ from a societal perspective. The cost per DALY averted was $\$ 68.31 "$.

The online version of the original article can be found under doi: 10.1007/s10029-008-0460-3.

M. G. Clarke · C. Oppong · A. N. Kingsnorth ( ()

Department of General Surgery,

Derriford Hospital, Plymouth PL6 8DH, UK

e-mail: andrew.kingsnorth@phnt.swest.nhs.uk

R. Simmermacher

Department of Surgery, University Medical Centre,

P.O. Box 85500, 3508 Utrecht, The Netherlands

K. Park

Department of Surgery,

Aberdeen Royal Infirmary, Aberdeen AB25 2ZN, UK

M. Kurzer

British Hernia Centre, 87 Watford Way,

London NW4 4RS, UK

L. Vanotoo

P.O. Box 202, Sekondi, Ghana 